\title{
Preparation and characterization of hyperbranched polyimides based on 4,4',4'"-triaminotriphenyl-methane
}

\author{
Petr Sysel, Evgenia Minko, Radana Čechová \\ *Department of Polymers, Institute of Chemical Technology, Technická 5, 16628 \\ Prague 6, Czech Republic; fax: +420220443175; e-mail: Petr.Sysel@vscht.cz
}

(Received: 19 September, 2008; published: 21 June, 2009)

\begin{abstract}
This work focuses on the preparation and characterization of novel hyperbranched polyimides based on commercially available 4,4,4"'triaminotriphenylmethane and pyromellitic dianhydride or 4,4'-oxydiphthalic anhydride. The bi- and trifunctional monomers were reacted in a molar ratio of $1: 1$ or 2:1 to prepare polyimide precursors (hyperbranched polyamic acids) endcapped with either amino or anhydride groups. The precursors were then transformed into hyperbranched polyimides using thermal imidization. The final products were self-standing films, whose thermal behaviour was characterized by having no weight loss up to $250^{\circ} \mathrm{C}$ and by having glass transition temperatures above $200^{\circ} \mathrm{C}$. We monitored the permeability of carbon dioxide, organic vapours and water vapour through these membranes. We also compared the properties of these materials with linear polyimides based on 4,4'-methylenedianiline combined with either pyromellitic dianhydride or 4,4'-oxydiphthalic anhydride.

Key Words: hyperbranched polyimides, 4,4,'4"-triaminotriphenylmethane
\end{abstract}

\section{Introduction}

Aromatic polyimides are an important class of high performance polymers. Linear and crosslinked aromatic polyimides exhibit excellent chemical, mechanical and dielectric stability, even at elevated temperatures up to $250^{\circ} \mathrm{C}$. They are mostly used in the (micro) electronics and aircraft industries, as well as in space exploration and polymeric separation technologies [1]. In the last decade various authors have considered how hyperbranched polyimides (HBPI) might be used to extend the application of this type of polymeric material [2-6].

In the field of synthetic polymers dendritic topology has become recognized as a new class of macromolecular architecture alongside the traditional linear, branch and crosslinked structures. Dendritic polymers can be organized as highly symmetrical dendrimers or as irregular hyperbranched polymers. The main disadvantage of dendrimers is that their preparation requires use of a multistep procedure, whereas hyperbranched polymers can be prepared by the direct one-step polymerization of multifunctional monomers. Consequently, such polymers show great potential for use in a wide range of industrial applications (e.g. drug delivery, coatings) [7].

Because polyimides are insoluble in most common solvents and generally have high glass transition temperatures (approximately $200{ }^{\circ} \mathrm{C}$ and above), they are mostly processed in the form of their precursor - polyamic acid (PAA) [1]. The synthesis of a linear polyamic acid (LPAA) consists of the reaction of an aromatic diamine with an aromatic dianhydride in an aprotic polar solvent (e.g. N-methyl-2-pyrrolidone (NMP)). 
The final product, linear polyimide (LPI), is often prepared by thermal solid-state imidization of the LPAA (Fig. 1).

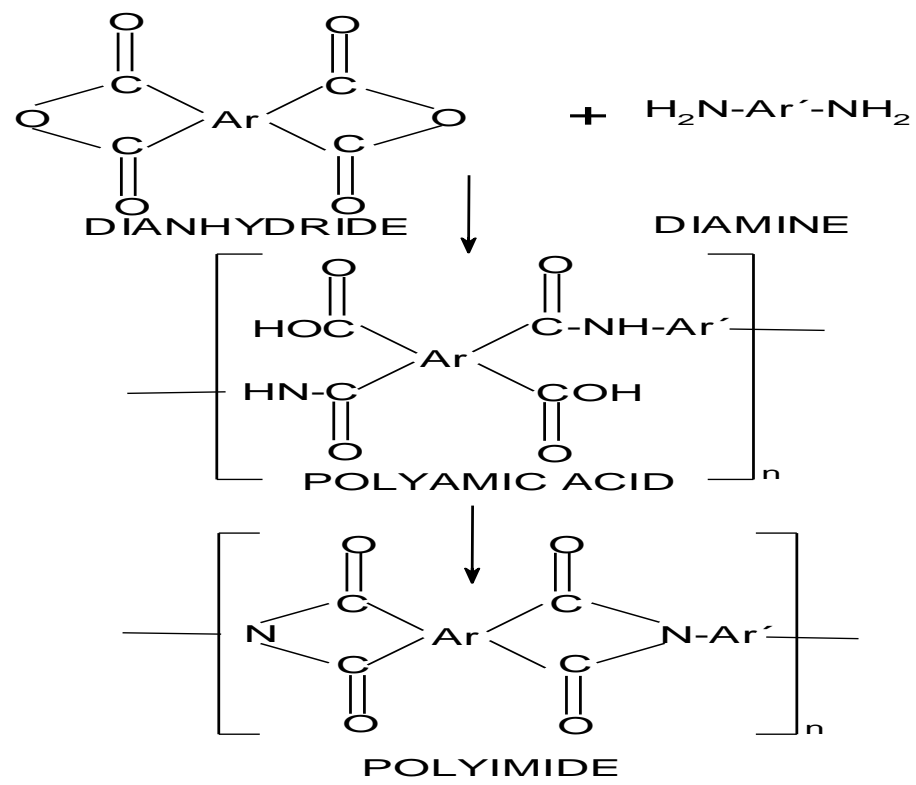

Fig. 1. Two-step preparation of polyimides.

One route to the creation of hyperbranched polymers involves the step-growth polymerization of an $\mathrm{AB}_{\mathrm{x}}$ monomer; $\mathrm{A}$ and $\mathrm{B}$ representing two kinds of functional groups that can react with each other, but cannot undergo a self-reaction, $x \geq 2$ [8]. However, it is difficult to obtain some $A B_{x}$ monomers, e.g. for the preparation of HBPls [2]. Although the $A_{2}$ (bifunctional monomer) $+B_{3}$ (trifunctional monomer) methodology can be used to solve this problem [2-8], it is known that direct polymerization of $A_{2}+B_{x}(x \geq 2)$ monomers generally results in a three-dimensional end product $[9,10]$. Besides, suitable trifunctional monomers (anhydrides, amines) are not almost commercially available.

In this study we prepare and characterize novel HBPIs based on commercially available 4,4,'4"-triaminotriphenylmethane combined with either pyromellitic anhydride or 4,4'-oxydiphthalic anhydride. We describe the optimum reaction conditions required to avoid gel formation. We show how the properties of HBPIs are dependent on their composition, and compare them with the properties of LPIs based on 4,4'-methylenedianiline combined with either pyromellitic dianhydride or 4,4'oxydiphthalic anhydride.

\section{Results and discussion}

HBPls are often prepared using a combination of monomers of the $A_{2}$ and $B_{3}$ types. Laboratory synthesized triamines and trianhydrides with a relatively complex structure have typically been used for this purpose [2, 5]. However, if the production of HBPIs is to be shifted from the laboratory scale to the industrial scale, monomers will need to be commercially available, and, currently, almost no suitable aromatic trianhydrides and triamines can be found on the market.

In previous studies, in which we used commercially available 2,4,6triaminopyrimidine as a $B_{3}$ monomer [12,13], our results supported the idea that the reactivity of the amino groups of 2,4,6- triaminopyrimidine is different in position 2 
compared with either position 4 or 6 [14]. Consequently, it is possible to consider the formation of an irregular hyperbranched polymer structure with a relatively low number of triaminopyrimidine units simultaneously connected in positions 2, 4 and 6 .

Therefore, the $B_{3}$ monomer used in this study was commercially available $4,4,44^{\prime \prime}$ triaminotriphenylmethane (MTA) (Fig. 2a), whose three amino groups are equivalent. Pyromellitic dianhydride (PMDA) (Fig. 2b) and 4,4'-oxydiphthalic anhydride (ODPA) (Fig. 2c) were used as the $A_{2}$ monomers. The polyimides prepared from PMDA and ODPA (together with the same diamine) were found to have quite different glass transition temperatures $\left(T_{g}\right)$ [15]. The flexible ether bridge in the ODPA molecule can favourably influence the preparation of HBPI self-standing films.

The preparation and properties of our HBPIs were compared with those of LPIs based on 4,4'- methylenedianiline (MDA) (Fig. 2d) combined with either PMDA in a molar ratio of 1:1 [LPI(PMDA-MDA)11] or ODPA in a molar ratio of 1:1 [LPI(ODPAMDA)11].

a)

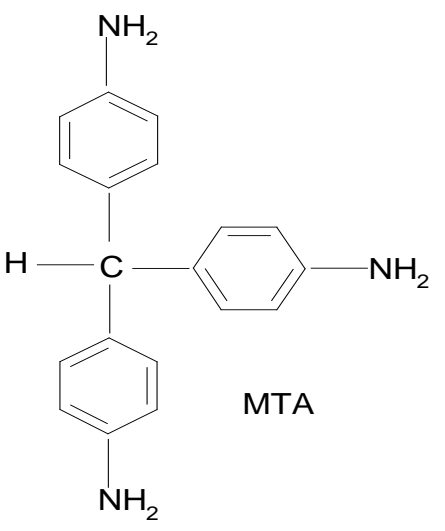

b)

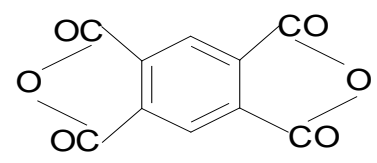

PMDA

c)

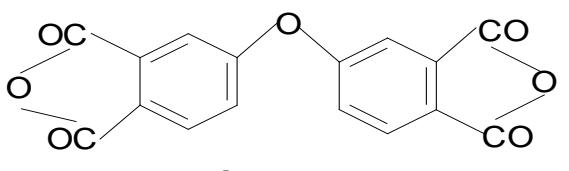

ODPA

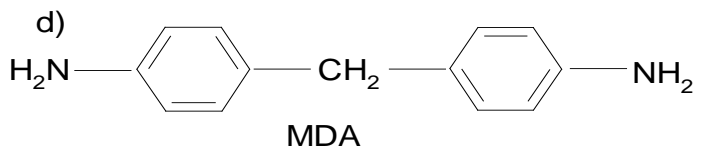

Fig. 2. Chemical structure of a) 4,4',4"-triaminotritriphenylmethane (MTA), b) pyromellitic anhydride (PMDA), c) 4,4'-oxydiphthalic anhydride (ODPA) and d) 4,4'methylenedianiline (MDA).

The molar amount of $A_{2}$ and $B_{3}$ monomers used in the preparation of HBPIs influences the kind and ratio of terminal groups. If the $A_{2}: B_{3}$ ratio $=1: 1$ (i.e. anhydride:amino groups = 2:3) amine end-capped HBPls are formed [HBPI(PMDA- 
MTA)11 (Fig. 3) and HBPI(ODPA-MTA)11]; if the ratio is 2:1 (i.e. 4:3) anhydride terminated HBPI [HBPI(PMDA-MTA)21 and HBPI(ODPA-MTA)21] are produced.

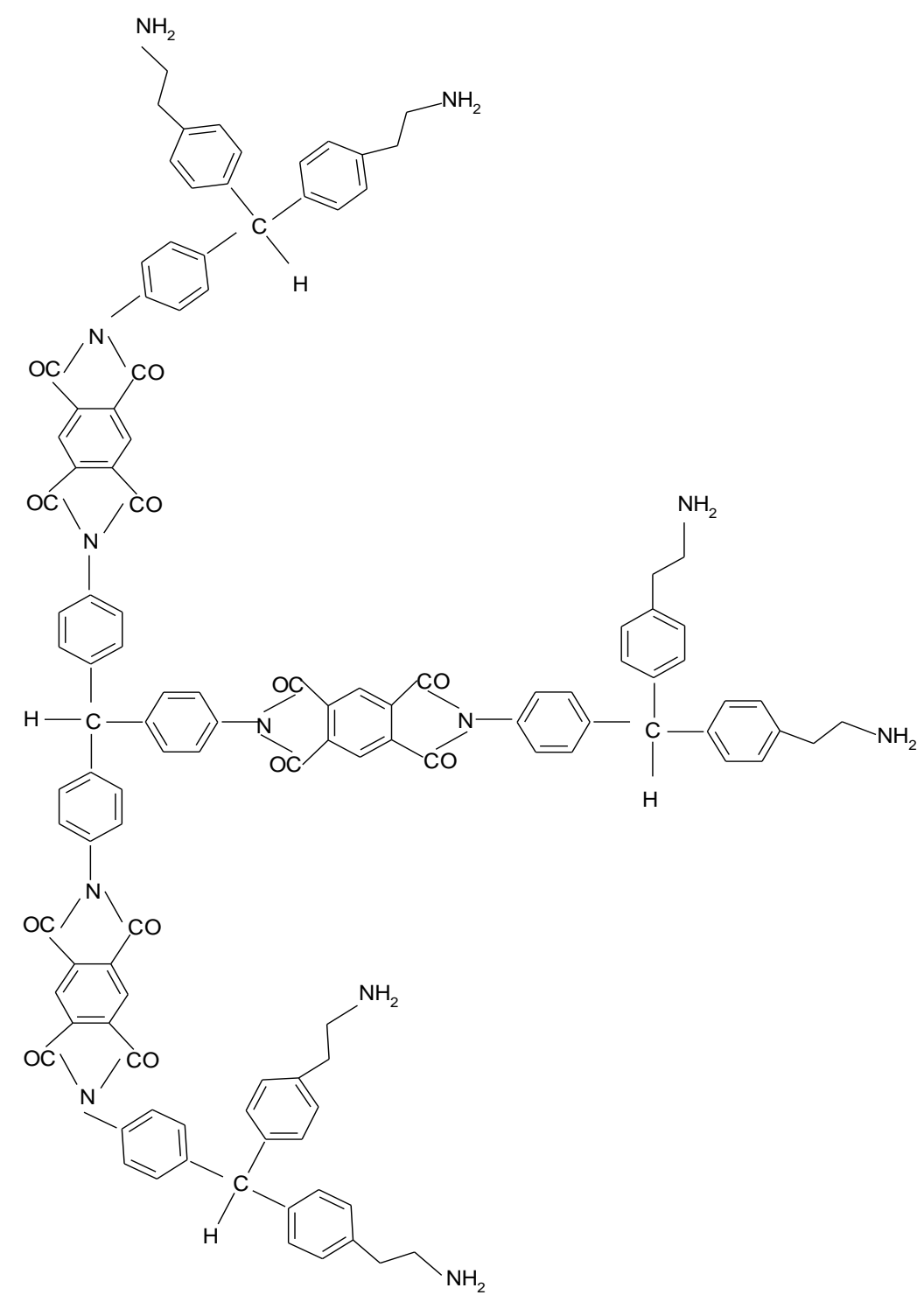

Fig. 3. Chemical structure of HBPI(PMDA-MTA)11.

When $\mathrm{A}_{2}$ and $\mathrm{B}_{3}$ monomers are used, a three-dimensional structure forms during the course of polymerization $[9,10]$. In our experiments the formation of this structure was suppressed by the slow dropwise addition of a dilute solution of one monomer to a solution of the other (see Experimental part); in both cases, a solution of a dianhydride in NMP being added to an MTA solution. For each polymer type, we recorded the highest concentration of solids found (Tab. 1), with higher concentrations leading to insoluble final products ((micro) gel). The same procedure (with a highest concentration of 6 wt $\%$ for PMDA-based LPAA, and 4 wt $\%$ for ODPAbased LPAA) was used for the preparation of linear analogues; the formation of three-dimensional product (gel) not being typical in this case. As Tab. 1 shows, a highest concentration of only 1 wt\% was found for anhydride end-capped HBPAA. The polyimide precursors could not be separated from such low-concentrated solutions, even though, in addition to traditional distilled water, we used methanol, ethanol and propanol as precipitating agents. Table 1 also displays the kinematic 
viscosities of the HBPAA and LPAA solutions, and the intrinsic viscosities (limiting viscosity numbers) of the polymers.

Tab. 1. Characterization of polyimide precursors: hyperbranched (HBPAA) and linear (LPAA) polyamic acids.

\begin{tabular}{llll}
\hline Polyamic acid & $c^{\mathrm{a}}(\mathrm{wt} \%)$ & $v^{\mathrm{b}}\left(\mathrm{m}^{2} \mathrm{~s}^{-1}\right)$ & {$[\eta]^{\mathrm{c}}\left(\mathrm{mlg}^{-1}\right)$} \\
\hline HBPAA(PMDA-MTA) $11^{\mathrm{d}}$ & 6 & $3.62 \times 10^{-5}$ & 47.9 \\
HBPAA(PMDA-MTA) 21 & 1 & $3.10 \times 10^{-6}$ & $-\mathrm{e}$ \\
HBPAA(ODPA-MTA) 11 & 4 & $3.17 \times 10^{-5}$ & 16.0 \\
HBPAA(ODPA-MTA) 21 & 1 & $2.23 \times 10^{-6}$ & --- \\
LPAA(PMDA-MDA) $11^{\dagger}$ & 6 & $2.98 \times 10^{-5}$ & 45.5 \\
LPAA(ODPA-MDA) 11 & 4 & $2.83 \times 10^{-5}$ & 35.5
\end{tabular}

${ }^{a}$ concentration of polyamic acid in NMP, ${ }^{b}$ kinematic viscosity of the solution of polyamic acid, ${ }^{c}$ limiting viscosity number (intrinsic viscosity), "hyperbranched polyamic acid based on PMDA and MTA in a molar ratio of $1: 1$, ${ }^{e}$ unsuccessful isolation of polyamic acid from solution, ${ }^{f}$ linear polyamic acid based on PMDA and MDA in a molar ratio of 1:1

In agreement with general assumption, the kinematic viscosities of the $1 \mathrm{wt} \%$ solutions of HBPAA were approximately one order lower than the other, more highly concentrated, solutions. Of course, solution viscosities can also be influenced by the molecular weight of dissolved polymers. The higher intrinsic viscosity values $[\eta]$ of PMDA-based HBPAA and PMDA-based LPAA in comparison with those obtained for the ODPA-based polyamic acids can be given by the differences in molecular weights and/or character of polymer coils in solution. However, the value $[\eta]$ of $16 \mathrm{ml}$ $\mathrm{g}^{-1}$ obtained for HBPAA(ODPA-MTA) 11 was unexpectedly low.

HBPAA and LPAA were transformed into HBPI and LPI, respectively, using thermal exposition up to $230{ }^{\circ} \mathrm{C}$ (see Experimental part). The obtained materials were analyzed by IR spectroscopy (Figs. 4-5). Fig. 4 shows the typical IR spectra obtained for both HBPAA(ODPA-MTA)21 and its corresponding HBPI. The absorption bands at 1777 and $1718 \mathrm{~cm}^{-1}$ (symmetric and asymmetric stretching of the ring carbonyl groups), together with the band at $1384 \mathrm{~cm}^{-1}$ (stretching of the ring $\mathrm{C}-\mathrm{N}$ bond), are distinct in the spectrum of HBPI(ODPA-MTA)21 and characterize the formation of imide structures. The absence of the band at $1687 \mathrm{~cm}^{-1}$ [amide group of polyamic acid - see the IR spectrum of HBPAA(ODPA-MTA)21] supports our notion that thermal treatment leads to almost complete imidization.

Fig. 5 compares the IR spectra of HBPI(ODPA-MTA) 11 and HBPI(ODPA-MTA)21. In addition to the characteristic polyimide absorption bands described above, the distinct band at $1622 \mathrm{~cm}^{-1}$ corresponds to terminal amino groups in the spectrum of $\mathrm{HBPI}(\mathrm{ODPA}-\mathrm{MTA}) 11$, and the band at $1851 \mathrm{~cm}^{-1}$ corresponds to terminal anhydride groups in the spectrum of HBPI(ODPA-MTA)21.

The resistance of these materials to selected solvents (NMP, heptane, toluene, methanol) was evaluated from their weight change after immersion in the respective media for 35 days. The final materials were insoluble in these media. The highest uptake of HBPI(PMDA-MTA)11 was found in NMP (75\%), while uptake was much lower in methanol and toluene $(10 \%)$ and heptane $(4 \%)$. The uptake of HBPI(ODPA-MTA)11 in NMP was markedly lower (10\%), and slightly lower in 
methanol (7\%), toluene $(1 \%)$ and heptane $(0 \%)$. This may be more a consequence of morphology than of chemical composition, the chemical stability of PMDA-based polyimides theoretically being higher than those based on ODPA [1]. Surprisingly, although HBPIs are known to be more soluble, their resistance to the tested solvents was comparable to that of the analogous LPIs [2,5].
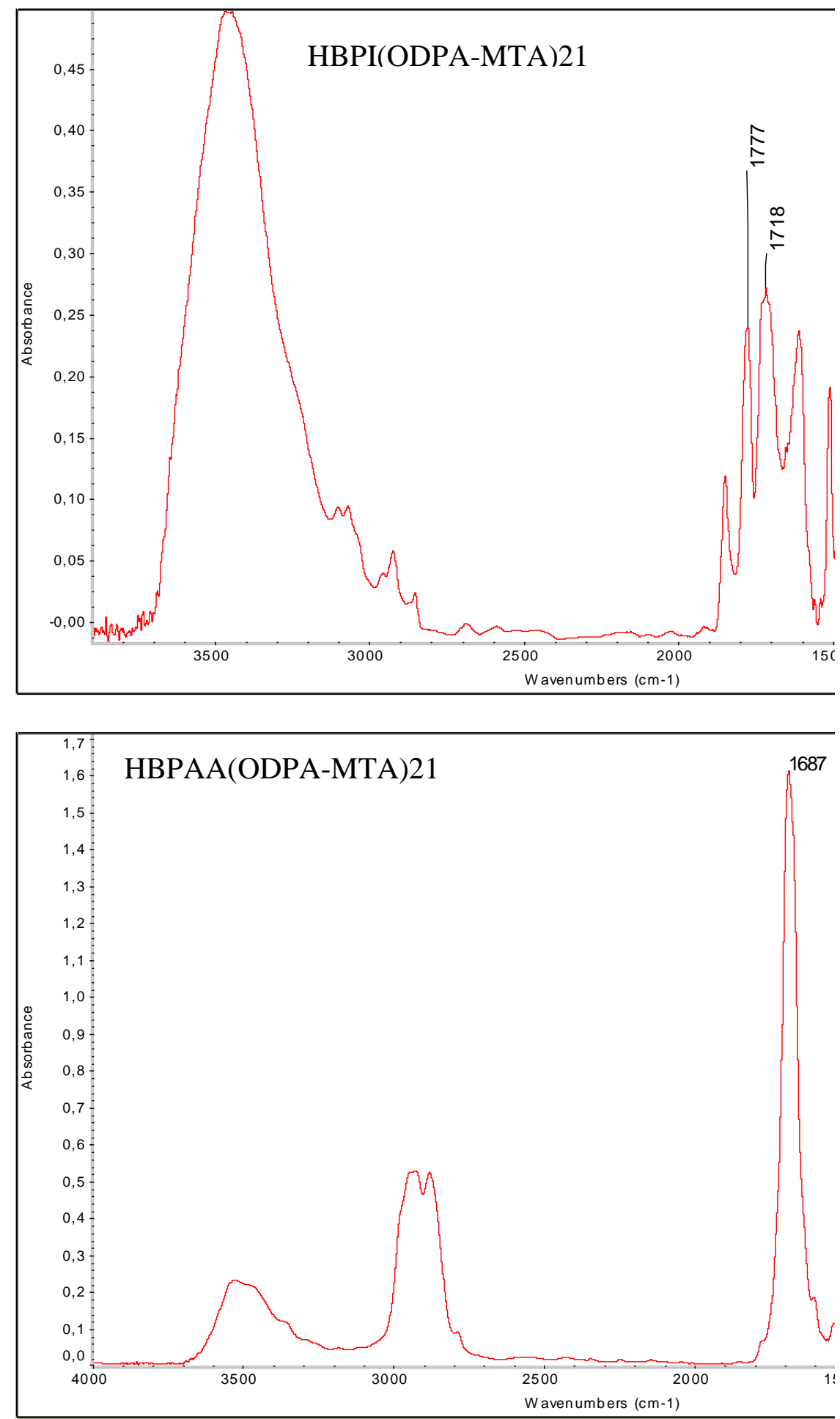

Fig. 4. IR spectra of $\mathrm{HBPI}(\mathrm{ODPA}-\mathrm{MTA}) 21$ (top) and HBPAA (ODPA-MTA)21 (bottom). 
For the both amine- and anhydride end-capped HBPIs, their ${ }^{1} \mathrm{H}$ NMR spectra were not obtained due to their insolubility. Therefore, we estimated the degree of branching using ${ }^{1} \mathrm{H}$ NMR analyses of their precursors (HBPAA). The degree of branching is defined as the ratio of the sum of dendritic and terminal units vs. total units (linear, dendritic, and terminal units) [2]. The signals in the region of 5-6 ppm corresponding to the hydrogen of methine group $(\mathrm{C}-\underline{\mathrm{H}})$ were used for this purpose. To make clear the assignment of the signals in this region, three model compounds from phthalic anhydride and MTA were prepared (see Experimental part) and analyzed by ${ }^{1} \mathrm{H}$ NMR spectroscopy. The degree of the amine end-capped HBPAA was evaluated to be slightly higher than 0.6 . In the spectrum of the anhydride endcapped HBPAA, one signal was only found in the region of 5-6 ppm. It supports the assumption that the degree of a such type of product should be close to 1 .
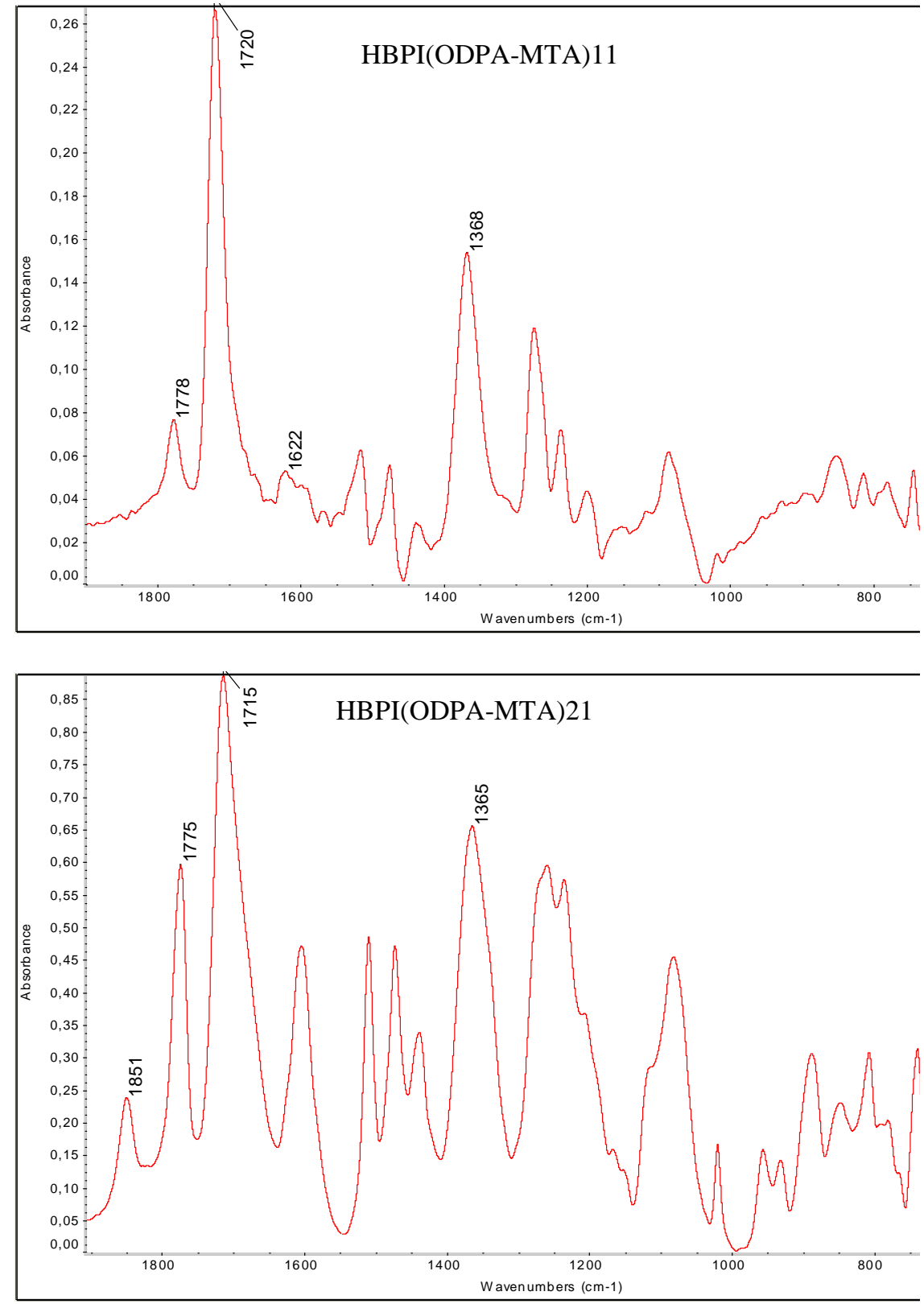

Fig. 5. IR spectra of HBPI(ODPA-MTA)21 (top) and HBPI(ODPA-MTA)11 (bottom). 
Tab. 2 presents the glass transition temperatures $\left(T_{g}\right)$, and the temperatures corresponding to $10 \mathrm{wt} \%$ weight loss during thermooxidative attack. In both cases, the $T_{g}$ of the amine end-capped HBPI was higher than that of the LPI based on the same dianhydride. Interactions between the terminal amino groups may be one reason for the higher $T_{g}$ of the amine-terminated hyperbranched structures. On the other hand, the thermooxidative stabilities (evaluated as the temperatures corresponding to $10 \mathrm{wt} \%$ loss during thermogravimetric analysis with a temperature gradient of $10^{\circ} \mathrm{C} \mathrm{min}^{-1}$ ) of the LPIs were higher than those of the corresponding HBPIs. The lower thermal stability of the HBPIs might be due to deficiencies in their chain entanglements resulting from a lower number of physical crosslinks [2]. The higher thermooxidative stability of amine end-capped HBPIs, compared to anhydride end-capped HBPIs, again could be the result of interactions between the terminal amino groups.

Tab. 2. Characterization of hyperbranched (HBPI) and linear (LPI) polyimides.

\begin{tabular}{|c|c|c|}
\hline Polyimide & $\mathrm{T}_{\mathrm{g}}{ }^{\mathrm{a}}\left({ }^{\circ} \mathrm{C}\right)$ & $\mathrm{T}^{\mathrm{b}}\left({ }^{\circ} \mathrm{C}\right)$ \\
\hline $\mathrm{HBPI}(\mathrm{PMDA}-\mathrm{MTA}) 11^{\mathrm{C}}$ & 423 & 523 \\
\hline HBPI(PMDA-MTA) 21 & & 452 \\
\hline HBPI(ODPA-MTA) 11 & 287 & 509 \\
\hline HBPI(ODPA-MTA)21 & --- & 375 \\
\hline LPI(PMDA-MDA) $11^{d}$ & 355 & 592 \\
\hline LPI(ODPA-MDA) 11 & 276 & 566 \\
\hline
\end{tabular}

${ }^{a}$ glass transition temperature, ${ }^{b}$ temperature corresponding to $10 \mathrm{wt} \%$ weight loss, "hyperbranched polyimide based on PMDA and MTA in a molar ratio of 1:1, dinear polyimide based on PMDA and MDA in a molar ratio of $1: 1$

We monitored the transport of carbon dioxide (permeability coefficient $0.6 \times 10^{-17} \mathrm{~m}^{2} \mathrm{~Pa}$ $\left.{ }^{1} \mathrm{~s}^{-1}\right)$, toluene vapours $\left(2.96 \times 10^{-17} \mathrm{~m}^{2} \mathrm{~Pa}^{-1} \mathrm{~s}^{-1}\right)$, heptane vapours $\left(1.32 \times 10^{-17} \mathrm{~m}^{2} \mathrm{~Pa}^{-1} \mathrm{~s}^{-1}\right)$ and water vapour $\left(7.68 \times 10^{-16} \mathrm{~m}^{2} \mathrm{~Pa}^{-1} \mathrm{~s}^{-1}\right)$ through the HBPI(ODPA-MTA) 11 membrane. It seems that this HBPI is more permeable to the vapours of polar liquids (i.e. water). Unfortunately, we found virtually no increase in the permeability coefficient of carbon dioxide $\left(0.4 \times 10^{-17} \mathrm{~m}^{2} \mathrm{~Pa}^{-1} \mathrm{~s}^{-1}\right)$ compared with LPI(ODPAMDA)11. Thus, our results cannot be used to support the idea that cavities existing in the structure of rigid hyperbranched polymers influence the free volume of a polymer, and, consequently, other properties that depend on its free volume (i.e. permeability) $[2,3]$. It is, therefore, necessary to conduct further experiments to establish the potential of HBPIs as separation membranes.

\section{Conclusions}

Hyperbranched polyimides based on 4,4',4"-triaminotriphenylmethane and pyromellitic dianhydride or 4,4'-oxydiphthalic anhydride were prepared in the form of thin self-standing films. By varying in the concentration of monomers the amine or anhydride terminated products were synthesized. Their hyperbranched structure was supported by finding the high degrees of branching. The amine end-capped hyperbranched polyimide had the higher thermooxidative stability compared to anhydride terminated one. Nevertheless, the thermooxidative stability of both types of hyperbranched polyimides was lower compared to the corresponding linear 
analogues. The amine terminated hyperbranched product showed nearly by one order higher permeability coefficient of water than of toluene and heptane.

\section{Experimental part}

\section{Materials}

Pyromellitic dianhydride (PMDA) and 4,4'-oxydiphthalic anhydride (ODPA) (both Aldrich, Czech Republic) were heated to $170{ }^{\circ} \mathrm{C}$ for $5 \mathrm{~h}$ in a vacuum before use. 4,4'Methylenedianiline (MDA) (Aldrich) and 4,4',4'-triaminotriphenylmethane (MTA) (Dayang Chemicals, China) were used as received.

MTA elemental analysis: theor.: C 78.90\%, H 6.57\%, N 14.53\%

found: C $77.35 \%, \mathrm{H} 6.90 \%, \mathrm{~N} 14.52 \%$

MTA melting point: $\quad$ m. p. (theor.) $201^{\circ} \mathrm{C}$ (ref. [11])

m.p. (exper.) $198-201^{\circ} \mathrm{C}$

1-Methyl-2-pyrrolidone (NMP) (Merck, Czech Republic) was distilled under vacuum over phosphorus pentoxide, and stored in an inert atmosphere.

\section{Preparation}

All glassware was dried at $120{ }^{\circ} \mathrm{C}$ for $3 \mathrm{~h}$ prior to use. Hyperbranched polyamic acids (HBPAA) and LPAA were prepared in a $250 \mathrm{ml}$ two-necked flask equipped with a magnetic stirrer and a nitrogen inlet/outlet. We followed the general procedure for the preparation of amine end-capped HBPAA based on PMDA and MTA [HBPAA(PMDA-MTA)11].

At room temperature, a solution of $3.438 \mathrm{~g}(0.016 \mathrm{~mol})$ PMDA in $65 \mathrm{ml}$ of NMP was added dropwise to a solution of $4.562 \mathrm{~g}(0.016 \mathrm{~mol})$ of MTA in $86 \mathrm{ml}$ of NMP for approximately $45 \mathrm{~min}$. This reaction mixture was then stirred at room temperature for $24 \mathrm{~h}$.

A solution of either HBPAA or LPAA in NMP was spread onto a glass substrate. The resulting thin layer (tenths of millimetres thick) was kept at $60{ }^{\circ} \mathrm{C} / 12 \mathrm{~h}, 100{ }^{\circ} \mathrm{C} / 1 \mathrm{~h}$, $150{ }^{\circ} \mathrm{C} / 1 \mathrm{~h}, 200^{\circ} \mathrm{C} / 2 \mathrm{~h}$ and, finally, at $230^{\circ} \mathrm{C} / 1 \mathrm{~h}$. The thickness of the transparent reddish self-standing films obtained was about $50 \mu \mathrm{m}$.

Model compounds were prepared from phthalic anhydride and MTA at the molar ratio $1: 1,2: 1$ and $3: 1$, respectively using $d_{6}$-DMSO as a solvent. (These precursors were also imidized by heating at $160{ }^{\circ} \mathrm{C}$ for $24 \mathrm{~h}$ after addition of $\mathrm{d}_{10}$-xylene as an azeotropic agent). The samples were directly analyzed using ${ }^{1} \mathrm{H}$ NMR spectroscopy.

\section{Characterization}

${ }^{1} \mathrm{H}$ NMR spectra were taken on Bruker Avance DRX 500 at $500 \mathrm{MHz}$ in $\mathrm{d}_{6^{-}}$ dimethylsulfoxide. IR spectra were recorded on a Nicolet 740 spectrometer using either liquid samples (solutions of polyamic acids) or $\mathrm{KBr}$ pellets (solid polyimides). Dynamic thermogravimetric measurements were performed in air using a TG-750 Stanton-Redcroft (heating rate $10^{\circ} \mathrm{C} \mathrm{min}^{-1}$ ). Dynamic mechanical analysis (DMA) was performed using a DMA DX 04T (RMI, Bohdaneč, Czech Republic) at $1 \mathrm{~Hz}$ as the temperature rose from room temperature to $450{ }^{\circ} \mathrm{C}$; the temperature gradient being $3{ }^{\circ} \mathrm{C} \mathrm{min}^{-1}$. We used the following procedure to test the chemical resistance of 
the materials in the NMP, as well as in methanol and toluene: each film was dried at $100{ }^{\circ} \mathrm{C}$ for $3 \mathrm{~h}$, weighed, and immersed in an appropriate solvent. After 35 days the weight change was determined. The kinematic viscosities of the HBPAA and LPAA solutions were measured using a capillary viscometer at $20{ }^{\circ} \mathrm{C}$, and their intrinsic viscosities measured in NMP at $25^{\circ} \mathrm{C}$.

We measured the permeation of carbon dioxide, organic vapours and water vapour at $25^{\circ} \mathrm{C}$ using a specially constructed differential flow permeameter. The membrane was fixed in a permeation cell and put into contact with a mixture of a gas or vapour with hydrogen (carrier gas) at a constant pressure. The penetrating gas (vapour) from the downstream (feed) side of the membrane to upstream side was from upper department of cell carried away by a stream of pure hydrogen. Changes of thermal conductivity of hydrogen (due to gas (vapour) permeation were monitored by a pair of the thermal conductivity detectors built into the Wheatstone resistance bridge. The reference thermistor is in permanent contact with pure carrier gas while the measuring one is in contact with mixture of permeant and hydrogen. A stable voltage signal from resistance bridge was obtained until reaching of steady-state.

\section{Acknowledgements}

This work was supported by the Grant Agency of the Czech Republic through grant No. 203/06/1086 and research program MSM 6046137302. A fruitful discussion with professor J. Kralicek is highly acknowledged.

\section{References}

[1] Hergenrother, P.M. High Perform. Polym. 2003, 15, 3.

[2] Fang, J.; Hidetoshi, K.; Okamoto, K. Macromolecules 2000, 33, 4639.

[3] Fang, J.; Hidetoshi, K.; Okamoto, K. J. Membr. Sci. 2001, 182, 245.

[4] Hao, J.; Jikei, M.; Kakimoto, M. Macromolecules 2003, 36, 3519.

[5] Jikei, M.; Kakimoto, M. J. Polym. Sci., Part A: Polym. Chem. 2004, 42, 1293.

[6] Suzuki, T.; Yamada, Y.; Tsujita, Y. Polymer 2004, 45, 7167.

[7] Tomalia, D. A. Aldrichimica ACTA 2004, 37(2), 39.

[8] Gao, C.; Yan, D. Prog. Polym. Sci. 2004, 29,183.

[9] Flory, P.J. J. Am. Chem. Soc. 1952, 74, 2718.

[10] Odian, G.; Principles of polymerization, 4th ed. New York: John Wiley \& Sons, 2004 (chapter 2).

[11] Hellwinkel, D.; Fritsch, H. Chem. Ber. 1990, 123, 2207.

[12] Bershtein, V.A.; Egorova, L.M.; Yakushev, P.N.; Sysel, P.; Hobzova, R.; Kotek, J.; Pissis, P.; Kripotou, S.; Maroulas, P. Polymer 2006, 47, 6765.

[13] Maroulas, P.; Kripotou, S.; Sysel, P.; Hobzova, R.; Kotek, J.; Pissis, P. J. NonCrystal. Solids 2006, 352, 4800.

[14] Liu, Y.; Chung, T. J. Polym. Sci.: Part A: Polym. Chem. 2002, 40, 4563.

[15] Chung, T.; Vora, R. H.; Jaffe, M. J. Polym. Sci. Part A: Polym. Chem. 1991, 29, 1207. 